\title{
Managing and Coping with Organizational Failure: Introduction to the Special Issue.
}

\section{Kamel Mellahi and Adrian Wilkinson}

\section{Introduction}

This special issue focuses on understanding the causes and management of organizational failure. Over the years far more organizations have failed than have succeeded. Yet, within business and management research, the study of organizational failure has always been considered as secondary to organizational success. Failure is commonly seen as being of less significance or, at best, as being complementary to research on organizational success. "Failure is the most fundamental feature of both biological systems and human social and economic organisations," as Ormerod (2005 p14 ) notes. "Of all the species that have ever existed, 99.99 per cent have failed in the most dramatic way. They are extinct. In America, more than 10 per cent of all companies fail every year, with more than 10,000 closing every week. Yet the existence of failure is one of the great unmentionables" (Ormerod, 2005: page 14). However, recently scholars from different disciplines including business history (Fridenson, 2005), economics (Ormerod, 2005), business management (Finkelstein, 2003; Wilkinson \& Mellahi, 2005), strategic management (Mellahi \& Sminia, 2009), and political science and law (Balleisen, 2001) have been calling for more research on business and organizational failure. This surge in interest in organizational failure is due in part to the wash up of the global financial crisis. High profile corporate failures caused by accounting frauds and deceits (e.g., Enron, Parmalat and WirldCom), fatal accidents (e.g., BP's Texas City refinery fire), environmental disasters (e.g., BP's oil leak in the Gulf of Mexico) and high levels corporate meltdowns as a result of the current global economic crisis (e.g., Northern Rock, AIG, and Freddie Mac) (Gillespie \& Dietz, 2009: 127) have thrown failure into sharp relief.

While the recent surge of interest in organizational failure is to be applauded, much of the research on organizational failure has been, and still is, largely fragmented across different disciplines. Understandably, scholars from different disciplines tackle different research questions, build on different theoretical bases, employ different methodological approaches, and often reach different conclusions. The result is a "Tower of Babel" effect, where there are different disciplinary voices, talking in different languages to different audiences about what causes organizational failure, the management of organizational failure, and how it might been prevented, avoided or rectified. Mellahi and Wilkinson (2004) warned that if this fragmentation is to continue, the field of organizational failure could itself be a failure-more of a "weed patch" than a "well-tended garden".

Even within the strategic management and organization studies field, in spite of the accumulated empirical evidence over the years, the field of organizational failure is getting bigger without necessarily maturing. With the exception of population ecology scholars (Hannan \& Freeman, 1984; Hannan, Barron, \& Carroll, 1991; Hannan, Carroll, Dobrev \& Joon, 1998; Carroll and Delacroix, 1982), strategic management and organization studies researchers have not yet marked out the boundaries of the field, nor have they developed, or reached a consensus on, an overarching theoretical framework to bring order to the current fragmented literature on organizational failure and organize future research agenda (Mellahi \& Wilkinson, 2004). As a result of this 
fragmentation, scholars interested in organizational failure tend to speak after one another, rather than to one another. This has impeded the accumulation of knowledge to enable the field of organizational failure to progress. One of the aims of this special issue is to advance our theoretical and empirical understanding of the causes and management of organizational failure and prompt a fruitful dialogue within the community.

The field of organizational failure is also hampered by a lack of a precise definition. Bygrave and Hofer (1991: 15) rightly noted that "good science has to begin with good definitions". The term 'failure' has multiple meanings attached to it in both lay and academic discourse, and this is apparent by exploring the different definitions in academic literature. Scholars use terms such as discontinuance, organizational death, exit, bankruptcy, retrenchment, setbacks to refer to failures within organizations. Building on prior definitions we propose that an organization fails when its ability to compete deteriorates as a consequence of actual or anticipated performance below a critical threshold that threatens its viability. Symptoms of organizational failure include market share erosion, persistent low or negative profitability, shrinking critical-that is financial, human and technological-resources, and/or loss of legitimacy.

Our definition excludes mild setbacks and does not consider them as failures. Further, based on this definition we can say that of the businesses that exit or discontinue their activities, only a small portion can be regarded as organizational failures. For example, consider the case of an organization disbanding an economically profitable element to release resources for ventures that are more lucrative or interesting. We do not consider such a deliberate action as a failure. Our definition echoes that of Gillespie and Dietz (2009: 128) who portrayed failure "as a single major incident, or cumulative series of incidents, resulting from the action (or inaction) of organizational agents that threatens the legitimacy of the organization and has the potential to harm the well-being of one or more of the organization's stakeholders". According to Gillespie and Dietz's definition of failure, "locus of control for the failure is internal to the organization, even though the context for the failure may involve external influences" and occurs as a result of "actions, or negligent inaction" from managers (p.129). This include mis-managing the renewal process, by for example, overdownsizing as a response to decline in performance creating an "organizational anorexia” where fewer people remain to carry out the tasks or creating what Bedeian and Armenakis (1988) called "the cesspool syndrome" where competent people leave the organization.

\section{Organizational Failure Research}

Organizational failure research has only recently made incursions into mainstream strategic management and organization studies. So far, research on organizational failure focuses predominantly on causes of organizational failure (Sheppard \& Chowdhury, 2005, Mellahi, Jackson \& Sparks, 2002; Mellahi, 2005; Finkelstein, 2003; Anheier, 1999, Cameron, Sutton, \& Whetten, 1988), and organizational learning from, and during, failure (Yeo, 2010; Desai, 2010; Baumard \& Starbuck, 2005; Cannon \& Edmondson, 2005). This special issue includes two papers on causes of organizational failure, and two papers on learning from failure, a topic which so far has received only cursory attention.. 
Scholars categorize causes of organizational failure into external environmental causes and internal causes (Mellahi \& Wilkinson, 2004). External causes of failure are classified into two broad categories: gradual changes in the business environment, and abrupt transformations of the business environment. Gradual shifts in the business environment are often caused by the interaction of a number of small changes in the business environment. If not identified early and dealt with properly, the gradual changes in the business environment may put organizations on a slippery slope towards organizational failure. Chaos theory is a powerful framework for understanding such organizational failures and breakdowns (Farazmand, 2003; Thietart \& Forgues, 1995). It has been widely used to explain the non-linear, accumulative and multidirectional interaction between minor events that may take place in the margins outside the organization's "warning radar system" (Thietart \& Forgues, 1995), and how these interactions results in disproportionate impact on organizations. Seeger (2002: 332) argued that all organizations operating in a complex environment "even those with the outward of long term stability and order, have the potential for bifurcation". That is, all organizations at all times are in a state of near failure and any small event has some probability of cascading into a large failure (Glieck, 1988).

Gradual change in the business environment that causes major failure is similar to Steward's (1989) butterfly effect argument that the flapping of a single butterfly's wings produces a minor change in the state of the atmosphere which over time, can result in a sufficiently major disruption of the atmosphere such that a tornado that otherwise would not have happened, happens, the converse. Similarly, some organizational failures are caused by minor, often sudden, event or series of events, in the organization or the environment within which the organization operates. Given its insignificance, this event (or combination of events), would not be noticed by management-because they are intractable-and if they did notice it they would typically leave it aside it or dismiss it as unexplainable event. This minor event, however, would interact non-linearly with other events and over time, would cause disproportionate damage to the organization.

This perspective implies, implicitly, that managers are powerless in predicting failure and helpless in dealing with its causes (Thietart \& Forgues, 1995). Mellahi and Wilkinson (2004) noted that given the complexity, randomness, and inherently unpredictable events that can cause failure, it is often impossible for managers to predict the time and magnitude of organizational failure reliably and accurately. In addition, according to chaos theory, failure does not occur in a continuum, but rather it takes place abruptly, often in a discrete manner (Thietart \& Forgues, 1995: 25). There is no major visible jolt/shock in the environment or noticeable internal trigger that initiated organizational failure. Rather, failure starts from a small seedsomething triggers the process - and caused by a culmination of events over a long period.

Alternatively, the abrupt transformations process involves a sudden event or a condition (or a series of events or conditions) that causes the organization to rapidly disintegrate. This process encapsulates that does not evolve gradually, over, for example, years, but rather happens within a distinctly brief period of time which gives management little time to react. Abrupt transformations include radical technological 
changes that alter the competitive environment within an industry, economic crises, and radical political change.

The core argument of those who advocate that failure is primarily caused by internal factors is that failure is a consequence of managers' inadequacies in dealing with external threats (Gillespie \& Dietz, 2009; Mellahi, Jackson \& Sparks, 2002), and a result of misguided actions that hasten the organization demise (Choi, Anderson \& Veillette, 2009; du Plessis, 2008; Mellahi, 2005). As Barmash (1973: 299) puts it, "corporations are managed by men; and men, never forget, manage organizations to suit themselves. Thus corporate calamities are calamities created by men” (sic).

When individuals or managers face adverse conditions such as a threat of failure, their behaviors can vary along two main dimensions: commission or omission. Action refers on the extent to which managers are aware of the threat - consciously or otherwise - and actively deal with it. Omission refers to the extent to which managers can cognitively distract from and actively seek to sustain the status quo. Research shows that managers may label and describe similar adverse conditions differently. Some managers may be more attentive to even quite weak signals which other managers fail to perceive. Furthermore, managers appraise and evaluate adverse conditions differently, and differ in how readily they conclude that strong or weak signals are indicative or symptoms of failure. Generally, managers are more likely to act when they understand and are able to deal with the issue at hand (Dutton, 1993). In contrast, according to threat-rigidity effect theory, managers in confusing and threatening situations, such as a crisis, tend to behave rigidly (Staw, Sandelands \& Dutton, 1981), and rather than conduct a serious analysis of the causes of crisis and develop innovative strategies to deal with it, they tend to cling to old ways of doing things and increase their use of cognitive simplification processes such as heuristics or 'rules of thumb'.

In many cases the reality of environmental changes cannot be ignored especially when the underlying profitability of the organization is affected (Grinyer, Hayes, \& McKiernan, 1988). However, even when managers realize that the external world has changed and seek to align the organization with the new business realities, a number of factors constrain the extent to which, and how fast, organizations can change. At the organizational level, over time collective organizational routines develop within organizations and become deeply embedded to allow organizations to exploit their existing competences and adapt to their environment. But, when the business environment shifts and new competences are needed, existing routines lead to inertia in the organization and hinders the organization's ability to realign itself with the new business environment (Barnett \& Pontikes, 2008, Barnett \& Freeman, 2001; Cohen \& Bacdayan, 1994; Sun, Mellahi, \& Thun, 2010).

At the individual level organizational and social psychologists have long reported an "omission bias" in decision making in a threat of failure situations. Omission bias refers to the tendency towards "the choice of a potentially harmful omission over a potentially less harmful act” (Ashc et al 2004) (Asch Names..., 1994). Kahneman, Slovic \& Tversky (1982) argued that, in contexts of uncertainty and risk, people perceive taking action is more abnormal than inaction. This is partly due to the fact that people tend to judge acts to be worse than omissions with the same consequences. Similarly, Samuelson and Zeckhauser (1988) reported that there is an exaggerated 
preference for maintaining the current state of affairs. In the same vein, Kahneman, Knetsch,

and

Thaler, (1991) reported that people in risky situations favor inaction over action and the status quo over alternative changes because the successes and advantages of changing the status quo are weighted less than the possible disadvantages.

\section{Overview of the Issue}

In this edition Francis and Zheng observe that organisations are often encouraged to learn from the failure of others but that failure is a very complex phenomenon and learning the lessons is not always straightforward. They argue that the extant literature, while stating the importance of such learning, is unclear as to the process by which this happens. Much depends on the process of vicarious learning, including how learning happens and the conditions that lead to successful learning and the conditions which preclude this taking place. They focus on two conditions of learning, cause attribution and lesson implementation, to develop a model illustrating enabling and inhibiting conditions. Drawing on the development of soccer in the USA and the attempt of the Major Soccer league to learn from the experience of the North American Soccer League, they examine learning and failure in several aspects namely, control, the use of foreign players, media relations and league profit. They then look at the wider implications of their work for the field.

In the second paper, Elliott and Macpherson examine the subject of learning from crisis using the case study of flood response in the UK. They argue that organizations struggle to learn from crisis and are often ill prepared when faced with sudden, high impact events. Their case study details an organisation that had previously been an award winner for emergency preparedness best practice, but the case study explores an instance where it delivered an inadequate response." They suggest that such learning prepares us only to replay our learning to make sense of and enact practice in a similar scenario. It is only when a breakdown of coping occurs that one becomes aware of the inadequacy of our established practices. As such, it follows that policies and agreed standards represent only current understandings of what constitutes 'best practice' following learning from crisis. Their usefulness may be challenged if they do not support appropriate practices during a subsequent event. Indeed they suggest best practice may even hinder recovery during the unpredictable events. They reconceptualise the crisis learning processes and suggest a future research agenda.

Hughes, Hughes and Morgan note that the strategic management literature is full of studies providing models of high performance and avenues to success, yet research is relatively silent on the causes of failure. While research into new product and project failures and organizational failure is relatively well populated, attempts to address the issue of strategy failure are few and far between. Strategy failure can be a cause in itself of organizational failure, but strategy failure may not necessarily lead inevitably to absolute organizational failure, Hughes et al argue. They seek to address the question of how strategy failure occurs in organizations that are predisposed toward changing or persisting with current strategy. They contend that structural and managerial antecedents of strategy failure exist and the extent to which these determine failure is different under conditions of high and low adherence to strategy.

Amankwah-Amoah and Debrah note that while the subject of organisational failure has led to a stream of research, most studies have focused on firms in the private 
sector and in developed economies. But globalisation has eased restrictions on once protected markets in developed and developing countries. Using a case study of Ghana Airways, this paper examines the causes of failure of state-owned organisations in developing countries. They develop an integrated framework of internal and external factors to aid the understanding of the causes of failure. The study found that internal factors such as frequent changes of the top management team, lack of clear business strategy and decision makers' characteristics combined with external factors such as liberalisation and currency fluctuations to cause the collapse of Ghana Airways. In addition, there were failures on the part of senior management to recognise and respond to clear signals that liberalisation would increase competition. It is thus argued that Ghana Airways collapsed partly because of the top managers' failure to properly define and ascertain the conditions of their environment.

DeVaughn and Leary notes that earlier work identifies a divide between more externally driven "deterministic" views of failure and more internally driven "voluntaristic" views which have left a gap in the literature in relation to mezzo-level explanations of failure, such as those examining the role of group level factors. Moreover, while there has been much focus on organizational failure , less attention has been paid to important antecedent states of failure and alternative types of failurerelated experiences that are short of complete failure They examines ownership concentration, organizational structure, and founding team experience as predictors of organizational distress, a pre-failure state defined as measurable decreases in performance over a three year period, among recently chartered banks in the U.S. banking industry. They reports that increased ownership concentration decreases organizational distress while more complex organizational structures increase it.

In conclusion, the five papers in this special issue fall into the bailiwick of strategic management and organization studies. Taken together, this collection suggests that organizational failure research not only can push beyond conventional strategy and organizational studies frameworks to reveal new insights on how organizations learn and adapt to changes in the business environment, but have the capacity to open up new areas of inquiry.

Acknowledgment

We offer our thanks to Reviewers and Authors involved in the special issue project, and to GOM Editor Yehuda Baruch for his support throughout the project.

\section{List of reviewers}

Dr Mat Hughes, The University of Nottingham, The University of Nottingham

Business School

Professor Barker Vincent, University of Kansas, School of Business.

Professor Shamsud Chowdhury, Dalhousie University, School of Business

Administration.

Professor Bradley Barnes, The University of Sheffield, The Management School.

Dr Pauline Jas, The University of Nottingham, School of Sociology and Social Policy 
Dr Gavin Schwarz, The University of New South Wales, Australian School of Business

Professor Veronique Ambrosini, The University of Birmingham, Birmingham

Business School

Dr Harry Sminia, The University of Sheffield, The Management School

Dr Palmer, Mark, Aston University, Aston Business School

Professor Allan McConnell, University of Strathclyde, Department of Government .

Dr Tina McGuinness, The University of Sheffield, The Management School

\section{References}

\section{References}

Anheier, H. K. (ed.) (1999). When Things Go Wrong. Organizational Failures and Breakdowns. Thousand Oaks, London, New Delhi, Sage.

Asch D. A, Baron, J., Hershey, J.C., Kunreuther, H., Meszaros. J., Ritov, I., \& Spranca, M. (2004). Omission bias and pertussis vaccination. Medical Decision Making, 14(2), 118-23.

Bedeian, A. G., \& Armenakis, A. A. (1998). The cesspool syndrome: How dreck floats to the top of declining organizations. Academy of Management Executive, 12, 58-63.

Balleisen, E. J. (2001). Navigating Failure: Bankruptcy and Commercial Society in Antebellum America. Chapel Hill, London, University of North Carolina Press.

Barmash, I. (1973). Great Business Disasters. New York, Ballantine Books.

Barnett, W.P. \& Freeman, J. (2001). Too Much of a Good Thing? Product Proliferation and Organizational Failure. Organization Science, 12(5), 539-558.

Barnett, W.P. \& Pontikes, E.G. (2008). The Red Queen, Success bias, and Organizational Inertia. Management Science, 54(7), 1237-1251.

Baumard, P. \& Starbuck, W.H. (2005). Learning from failures: Why it may not happen. Long Range Planning, 38(3), 281-298.

Bygrave, W.D \& Hofer, C.W. (1991). Theorizing about entrepreneurship. Entrepreneurship Theory Practice, 16(2), 13-22.

Cameron, K.A., Sutton, R.I. \& Whetten, A.D. (1988). Readings in Organizational Decline: Frameworks, Research, and Prescriptions. Cambridge, MA, Ballinger.

Cannon, M. \& Edmondson, A.C. (2005). Failing to learn and learning to fail (intelligently): How great organizations put failure to work to improve and innovate. Long Range Planning, 38(3), 299-319.

Carroll, G. \& Delacroix, J. (1982). Organizational mortality in the newspaper industries of Argentina and Ireland: an ecological approach. Administrative Science Quarterly, 27, 169-198

Choi, J. N. Anderson, T. A. \& Veillette, A. (2009). Contextual inhibitors of employee creativity in organizations: The insulating role of creative ability. Group \& Organization Management, 34, 330-357.

Cohen, M. \& Bacdayan, P. (1994). Organizational routines are stored as procedural memory: evidence from a laboratory study. Organization Science, 5(2), 387-390.

Desai, V. (2010). Learning to learn from failures: the impact of operating experience on railroad accident responses. Industrial and Corporate Change, Forthcoming, doi:10.1093/icc/dtq019

du Plessis, C. J. A. (2008). Ethical failure under the agency logic: Grounding governance reform in a logic of value. Group \& Organization Management, 33, 781-804. 
Dutton, J.E. (1993). Interpretations on automatic: A different view of strategic issue diagnosis. Journal of Management Studies, 30(3), 339-357.

Farazmand, A. (2003). Chaos and transformation theories: A theoretical analysis with implications for organization theory and public management. Public Organization, 3, 339-372.

Finkelstein, S. (2003). Why Smart Executives Fail and What You Can Learn From Their Mistakes. New York, Portfolio Penguin Group.

Fridenson, P. (2004). Business failure and the agenda of business history. Enterprise and Society, 5, 562-82

Gillespie, N. \& Dietz, G. (2009). Trust repair after organization-level failure. Academy of Management Review, 34(1), 127-145

Glieck, J. (1988). Chaos: Making a New Science. London, Heinemann.

Grinyer, P. H., Hayes, D.G. \& McKiernan, P. (1988). Sharpbenders: The secrets of unleashing corporate potential. Oxford, Blackwell.

Hannan, M.T. \& Freeman, J.H. (1984). Structural inertia and organizational change. American Sociological Review, 49, 149-164

Hannan, M.T., Barron, D. \& Carroll, G.R. (1991). On the interpretation of dependence in rates of organizational mortality: a reply to Peterson and Koput. American Sociological Review, 56, 410-415.

Hannan, M.T., Carroll, R.G., Dobrev, S.D. \& Joon, H. (1998). Organizational mortality in European and American automobile industries, Part I: revisiting the effects of age and size. European Sociological Review, 14, 279-302.

Kahneman, D., Slovic, P., \& Tversky, A. (1982). Judgment Under Uncertainty: Heuristics and Biases. New York, Cambridge University Press.

Kahneman, D., Knetsch, J. \& Thaler, R. (1991). The Endowment Effect, Loss Aversion, and Status Quo Bias: Anomalies. Journal of Economic Perspectives, 5(1), 193-206.

Mellahi K. \& Wilkinson, A. (2004). Organizational failure: A critique of recent research and a proposed integrative framework. International Journal of Management Reviews, 5/6(1), 21-41.

Mellahi, K. (2005). The Dynamics of boards of directors in failing organizations. Long Range Planning, 38(3), 261-279.

Mellahi, K. \& Sminia, H. (2009). Frontiers of Strategic Management Research. International Journal of Management Reviews, 11(1), 1-7.

Mellahi, K., Jackson, P. \& Sparks, L. (2002). An exploratory study into failure in successful organizations: the case of Marks and Spencer. British Journal of Management, 13 (1), 15-30

Ormerod, P. (2005). It's time to consider the great unmentionable. The Times Higher Education Supplement, 25 March.

Ormerod, P. (2005). Why Most Things Fail. London, Faber and Faber Publishers.

Samuelson, W. \& Zeckhauser, R. (1988). Status Quo Bias in Decision Making. Journal of Risk and Uncertainty, 1(1), 7-59.

Seeger, W.M. (2002). Chaos and crisis: propositions for a general theory of crisis communication. Public Relations Review, 28(4), 329-337.

Sheppard, J.P. \& Chowdhury, S.D. (2005). Riding the wrong wave: Organizational failure as a failed turnaround. Long Range Planning, 38(3), 239-260.

Staw, B.M. (1976). Knee-deep in the big muddy: a study of escalating commitment to a course of action. Organizational Behaviour and Human Performance, 16, 27-44.

Steward, I. (1989). Does God Play Dice? The Mathematics of Chaos. Oxford, Basil Blackwell. 
Sun, P., Mellahi, K. \& Thun, E. (2010). The Dynamic Value of MNE Political Embeddedness: The Case of the Chinese Automobile Industry. Journal of International Business Studies, doi: 10.1057/jibs.2009.94.

Thiétart, R.A. \& Forgues, B. (1995). Chaos Theory and Organization. Organization Science, 6 (1), 19-31.

Wilkinson, A. \& Mellahi, K. (2005). Organizational failure: Introduction to the special issue. Long Range Planning, 38(3).233-238.

Yeo, R.K. (2010). Problems as Building Blocks for Organizational Learning: A Roadmap for Experiential Inquiry. Group \& Organization Management, 35(3) 243-275. 